\title{
Cross-sectional Analysis of Risk Factors for Surgical Site Infection Secondary to Spinal Internal Fixation via the Posterior Approach
}

\author{
XiangHui Dong \\ Shaanxi Provincial People's Hospital \\ Yongchun Zhou ( $\square$ yong_chunzhou@163.com ) \\ Shaanxi Provincial People's Hospital
}

\section{Research Article}

Keywords: Posterior spinal surgery, Surgical site infection, Risk factor, Prevention and treatment

Posted Date: January 12th, 2022

DOI: https://doi.org/10.21203/rs.3.rs-1198870/v1

License: (c) (1) This work is licensed under a Creative Commons Attribution 4.0 International License.

Read Full License 


\section{Abstract}

Backgroud: The aim of this study was to investigate the risk factors related to surgical site infection (SSI) secondary to spinal internal fixation via the posterior approach.

Methods: Patients who had undergone spinal internal fixation via the posterior approach at the spinal center of our hospital from January 2004 to December 2019 were selected in this cross-sectional study. Information about age, sex, body mass index (BMI), fused segment, hemoglobin concentration, serum albumin concentration, surgical duration, surgery beginning time, allogeneic blood transfusion, combined diabetes, peak blood glucose $72 \mathrm{~h}$ postoperatively $\geq 12 \mathrm{mmol} / \mathrm{L}$, smoking history, and blood loss were included. The factors related to SSI were analyzed using univariate and multivariate analyses. $P<0.05$ was considered to indicate statistical significance.

Results: Among the 4,350 patients, 66 had SSI, with an infection prevalence of $1.5 \%$. The subjects included 37 men and 29 women (age range, 22-84 y; average age, $47.4 \pm 12.8$ y). Univariate analysis showed that sex, BMl, fused segment, surgery beginning time, allogeneic blood transfusion, and smoking history were not correlated to infection $(P>0.05)$. However, age $>60 \mathrm{y}$, surgical duration $>3 \mathrm{~h}$, serum albumin concentration $<30 \mathrm{~g} / \mathrm{L}$, hemoglobin concentration $<80 \mathrm{~g} / \mathrm{L}$, combined diabetes, peak blood glucose $72 \mathrm{~h}$ postoperatively $\geq 12 \mathrm{mmol} / \mathrm{L}$, and blood loss $>1,000 \mathrm{~mL}$ were correlated with infection $(P<$ 0.05). Multivariate logistic regression analysis demonstrated that age $>60 \mathrm{y}$, surgical duration $>3 \mathrm{~h}$, hemoglobin concentration $<80 \mathrm{~g} / \mathrm{L}$, serum albumin concentration $<30 \mathrm{~g} / \mathrm{L}$, combined diabetes, and blood loss $>1,000 \mathrm{~mL}$ were significantly correlated with SSI secondary to spinal internal fixation via the posterior approach.

Conclusion: This study provides information on SSI secondary to spinal internal fixation via the posterior approach. We found that age $>60 \mathrm{y}$, surgical duration $>3 \mathrm{~h}$, hemoglobin concentration $<80 \mathrm{~g} / \mathrm{L}$, serum albumin concentration $<30 \mathrm{~g} / \mathrm{L}$, combined diabetes, and blood loss $>1,000 \mathrm{~mL}$ are directly correlated with SSI secondary to spinal internal fixation via the posterior approach. These findings may contribute to discussions and actions that may help to reduce SSI secondary to spinal internal fixation via the posterior approach in the short or medium term.

\section{Background}

Spinal internal fixation via the posterior approach is a commonly used surgical method for degenerative spinal diseases and spinal fractures in the clinical setting. However, the internal fixture implanted in the human body is a foreign body that increases the postoperative incidence of surgical site infection (SSI). At present, $\mathrm{SSI}$ is clinically defined as surgery-related infection within 1 year of internal fixation, including superficial infection, deep infection, and interstitial infection of organs and tissues [1]. Studies [2,3] have shown that the prevalence of SSI secondary to spinal internal fixation via the posterior approach is about $0.7-12 \%$. For some patients undergoing spinal internal fixation via the posterior approach and fusion, the 
internal fixtures need to be removed before the fixed segment meets the fusion standards because of severe infection, leading to the secondary loss of spinal stability.

In China, especially in Northwest China, due to the limited medical resources, infection after spinal surgery increases the economic burden on patients and cause severe physical and psychological trauma to patients $[4,5]$. Moreover, there is limited information about the risk factors related to SSI secondary to spinal internal fixation via the posterior approach in China. Understanding the specific factors of SSI secondary to spinal internal fixation via the posterior approach is important for helping in the prevention of postoperative spinal infection and can support hospitals and the government to improve the current situation of infection secondary to spinal internal fixation via the posterior approach. In this study, we aimed to observe the factors related to SSI secondary to spinal internal fixation via the posterior approach in order to provide a certain reference for the clinical prevention of surgical incision infection and to evaluate the demographic and clinical characteristics of patients.

\section{Patients And Methods}

\section{Study participants}

In this cross-sectional study, we collected the clinical data of patients who were undergoing spinal internal fixation via the posterior approach at the spinal center of our hospital and were diagnosed with postoperative spinal infection based on clinical manifestations (body temperature change, pain at surgical area, incision change), imaging examination (magnetic resonance imaging), laboratory examinations [routine blood test, c reactive protein(CRP), erythrocyte sedimentation rate (ESR)] and bacteriological culture. The following inclusion criteria were also applied: (1) postoperative follow-up of $>1 \mathrm{y},(2)$ availability of complete imaging and laboratory data, and (3) residence in Northwest China. As per the exclusion criteria, (1) patients with malignant spinal tumors, (2) patients without internal fixation, (3) patients with primary spinal infection, (4) patients with a previous history of spinal surgery and spinal tuberculosis, and (5) patients with abnormal immune systems were excluded. The study protocol was approved by the ethics review committee of Shaanxi Provincial People's Hospital (No. 2020-0127). All the patients provided written informed consent for the use and publication of data for research purposes. We confirm that all methods have been performed according to the relevant guidelines and regulations.

\section{Data collection}

These data were collected by trained personnel from Shaanxi Provincial People's Hospital between January 2004 and December 2019 under the guidance of the first author. The demographic data and surgery-related data were recorded. The demographic data of patients were obtained from their medical records, including age, sex, body mass index (BMI), serum albumin concentration, hemoglobin concentration, combined diabetes, peak blood glucose $72 \mathrm{~h}$ postoperatively $>12 \mathrm{mmol} / \mathrm{L}$, and smoking history. The surgery-related factors included intraoperative allogeneic blood transfusion, number of fused segments, blood loss, surgical duration, and beginning time of surgery.

Statistical analyses

Page $3 / 12$ 
The data were processed using SPSS 19.0. The measurement data are expressed as $x \pm s$ and analyzed using the independent sample t-test. The enumeration data are expressed as the number of cases and analyzed using the $\chi^{2}$ test. Important factors in the univariate and correlation analyses were included in the stepwise multiple linear regression. $P<0.05$ was considered to indicate statistical significance.

\section{Results}

A total of 4,350 patients were enrolled in this study, including 2,250 men and 2,100 women, with an age range of $19-90 \mathrm{y}$ (average age, $45.2 \pm 14.7 \mathrm{y}$ ). Among the 4,350 patients, 66 had SSI, with a prevalence rate of $1.5 \%$, including 37 men and 29 women (age range, $22-84$ y; average age, $47.4 \pm 12.8 \mathrm{y}$ ). The general condition of the patients is shown in Table 1.

Table 1

Patient demographics and disease characteristics

\begin{tabular}{|lll|}
\hline Characteristic & Patients & Postoperative infection \\
\hline Sex & & \\
\hline Male & 2250 & 37 \\
\hline Female & 2100 & 29 \\
\hline Age (y) & $19-90(45.2 \pm 14.7)$ & $22-84(47.4 \pm 12.8)$ \\
\hline Posterior cervical approach & 134 & 2 \\
\hline Posterior thoracic approach & 1540 & 22 \\
\hline Posterior lumbar approach & 2676 & 42 \\
\hline
\end{tabular}

\section{Univariate analysis}

Univariate analysis showed that sex, BMI, number of fused segments, surgery beginning time, smoking history, allogeneic blood transfusion, and postoperative drainage duration were not correlated with infection $(P>0.05)$. However, age $>60 \mathrm{y}$, surgical duration $>3 \mathrm{~h}$, serum albumin concentration $<30 \mathrm{~g} / \mathrm{L}$, hemoglobin concentration $<80 \mathrm{~g} / \mathrm{L}$, combined diabetes, peak blood glucose $72 \mathrm{~h}$ postoperatively $\geq 12$ $\mathrm{mmol} / \mathrm{L}$, and blood loss $>1,000 \mathrm{~mL}$ were correlated with infection $(P<0.05$, Table 2$)$. 
Table 2

Univariate analyses of factors related to SSI secondary to spinal internal fixation via the posterior approach

\begin{tabular}{|c|c|c|c|c|}
\hline & $\begin{array}{l}\text { Number of } \\
\text { cases }\end{array}$ & $\begin{array}{l}\text { Number of } \\
\text { infectious cases }\end{array}$ & $\begin{array}{l}\text { Rate of } \\
\text { infection (\%) }\end{array}$ & $P$ \\
\hline \multicolumn{5}{|l|}{ Age (y) } \\
\hline$\leq 60$ & 2670 & 26 & $1.0 \%$ & $\begin{array}{l}P> \\
0.05\end{array}$ \\
\hline$>60$ & 1680 & 40 & $2.4 \%$ & $\begin{array}{l}P< \\
0.05\end{array}$ \\
\hline \multicolumn{5}{|l|}{ BMI $\left(\mathrm{kg} / \mathrm{m}^{2}\right)$} \\
\hline$<30$ & 1689 & 28 & $1.7 \%$ & $\begin{array}{l}P> \\
0.05\end{array}$ \\
\hline $25-30$ & 1868 & 26 & $1.4 \%$ & $\begin{array}{l}P> \\
0.05\end{array}$ \\
\hline$>30$ & 793 & 12 & $1.5 \%$ & $\begin{array}{l}P> \\
0.05\end{array}$ \\
\hline \multicolumn{5}{|c|}{ Number of fused segments } \\
\hline$\leq 2$ & 2308 & 38 & $1.6 \%$ & $\begin{array}{l}P> \\
0.05\end{array}$ \\
\hline$>2$ & 2042 & 28 & $1.4 \%$ & $\begin{array}{l}P> \\
0.05\end{array}$ \\
\hline \multicolumn{5}{|c|}{ Beginning time of surgery } \\
\hline Surgery before 12 PM & 2256 & 32 & $1.4 \%$ & $\begin{array}{l}P> \\
0.05\end{array}$ \\
\hline Surgery after $12 \mathrm{PM}$ & 2094 & 34 & $1.6 \%$ & $\begin{array}{l}P> \\
0.05\end{array}$ \\
\hline \multicolumn{5}{|l|}{ Hemoglobin (g/L) } \\
\hline$<80$ & 1784 & 32 & $1.8 \%$ & $\begin{array}{l}P< \\
0.05\end{array}$ \\
\hline$\geq 80$ & 2566 & 34 & $1.3 \%$ & $\begin{array}{l}P> \\
0.05\end{array}$ \\
\hline \multicolumn{5}{|l|}{ Serum albumin (g/L) } \\
\hline$<30$ & 1140 & 35 & $3.1 \%$ & $\begin{array}{l}P< \\
0.05\end{array}$ \\
\hline$\geq 30$ & 3210 & 31 & $1.0 \%$ & $\begin{array}{l}P> \\
0.05\end{array}$ \\
\hline
\end{tabular}




\begin{tabular}{|c|c|c|c|c|}
\hline & $\begin{array}{l}\text { Number of } \\
\text { cases }\end{array}$ & $\begin{array}{l}\text { Number of } \\
\text { infectious cases }\end{array}$ & $\begin{array}{l}\text { Rate of } \\
\text { infection (\%) }\end{array}$ & $P$ \\
\hline \multicolumn{5}{|c|}{ Smoking history } \\
\hline Yes & 1883 & 28 & $1.5 \%$ & $\begin{array}{l}P> \\
0.05\end{array}$ \\
\hline No & 2467 & 38 & $1.5 \%$ & $\begin{array}{l}P> \\
0.05\end{array}$ \\
\hline \multicolumn{5}{|c|}{ Allogeneic blood transfusion } \\
\hline Yes & 2022 & 32 & $1.6 \%$ & $\begin{array}{l}P> \\
0.05\end{array}$ \\
\hline No & 2328 & 34 & $1.5 \%$ & $\begin{array}{l}P> \\
0.05\end{array}$ \\
\hline \multicolumn{5}{|c|}{ Surgical duration (h) } \\
\hline$>3$ & 1951 & 41 & $2.1 \%$ & $\begin{array}{l}P< \\
0.05\end{array}$ \\
\hline$\leq 3$ & 2399 & 25 & $1.0 \%$ & $\begin{array}{l}P> \\
0.05\end{array}$ \\
\hline \multicolumn{5}{|c|}{ Postoperative drainage duration (h) } \\
\hline$\leq 48$ & 1987 & 28 & $1.4 \%$ & $\begin{array}{l}P> \\
0.05\end{array}$ \\
\hline$>48$ & 2363 & 38 & $1.6 \%$ & $\begin{array}{l}P> \\
0.05\end{array}$ \\
\hline \multicolumn{5}{|c|}{ Diabetes } \\
\hline Yes & 983 & 34 & $3.5 \%$ & $\begin{array}{l}P< \\
0.05\end{array}$ \\
\hline No & 3367 & 32 & $1.0 \%$ & $\begin{array}{l}P> \\
0.05\end{array}$ \\
\hline \multicolumn{5}{|c|}{$\begin{array}{l}\text { Peak blood glucose } 72 \mathrm{~h} \text { after } \\
\text { surgery }(\mathrm{mmol} / \mathrm{L})\end{array}$} \\
\hline$\leq 12$ & 3781 & 47 & $1.2 \%$ & $\begin{array}{l}P> \\
0.05\end{array}$ \\
\hline$>12$ & 569 & 19 & $3.3 \%$ & $\begin{array}{l}P< \\
0.05\end{array}$ \\
\hline \multicolumn{5}{|c|}{ Blood loss (mL) } \\
\hline$\leq 1000$ & 3777 & 51 & $1.4 \%$ & $\begin{array}{l}P> \\
0.05\end{array}$ \\
\hline
\end{tabular}




\begin{tabular}{|lllll|}
\hline & $\begin{array}{l}\text { Number of } \\
\text { cases }\end{array}$ & $\begin{array}{l}\text { Number of } \\
\text { infectious cases }\end{array}$ & $\begin{array}{l}\text { Rate of } \\
\text { infection (\%) }\end{array}$ & $P$ \\
\hline$>1000$ & 573 & 15 & $2.6 \%$ & $\begin{array}{l}P< \\
0.05\end{array}$ \\
\hline
\end{tabular}

\section{Multivariate analysis}

Multivariate logistic regression analysis demonstrated that age $>60 \mathrm{y}$, surgical duration $>3 \mathrm{~h}$, serum albumin concentration $<30 \mathrm{~g} / \mathrm{L}$, hemoglobin concentration $<80 \mathrm{~g} / \mathrm{L}$, combined diabetes, and blood loss $>1,000 \mathrm{~mL}$ were significantly correlated with SSI secondary to spinal internal fixation via the posterior approach $(P<0.05$, Table 3$)$.

Table 3

Multivariate logistic regression analysis of factors related to SSI secondary to spinal internal fixation via the posterior approach

\begin{tabular}{|llllll|}
\hline & B & Wald & $P$ & OR & 95\% Cl \\
\hline Age $>60 \mathrm{y}$ & 1.096 & 4.836 & 0.029 & 2.98 & $1.144 \sim 7.959$ \\
\hline Surgical duration $>3 \mathrm{~h}$ & 2.893 & 44.356 & 0.012 & 11.183 & $7.764 \sim 14.701$ \\
\hline Serum albumin concentration $(<30 \mathrm{~g} / \mathrm{L})$ & 1.121 & 4.998 & 0.014 & 3.322 & $1.368 \sim 4.738$ \\
\hline Hemoglobin concentration $(<80 \mathrm{~g} / \mathrm{L})$ & 1.11 & 4.879 & 0.015 & 2.998 & $1.247 \sim 6.269$ \\
\hline Combined diabetes & 2.135 & 21.191 & 0.005 & 4.475 & $3.355 \sim 10.832$ \\
\hline Blood loss & 2.458 & 26.353 & 0.013 & 10.522 & $4.452 \sim 30.815$ \\
$>1000 \mathrm{~mL}$ & & & & & \\
\hline
\end{tabular}

\section{Discussion}

SSI secondary to spinal surgery is considered to be related to many factors [6, 7], some of which are related to the patients themselves, while some are related to the treatment methods. In this study, advanced age, surgical duration $>3 \mathrm{~h}$, serum albumin concentration $<30 \mathrm{~g} / \mathrm{L}$, hemoglobin concentration $<80 \mathrm{~g} / \mathrm{L}$, combined diabetes and blood loss $>1,000 \mathrm{~mL}$ were the independent risk factors of SSI after spinal surgery in our hospital. Some studies have shown that age is an important factor that affects the incidence of SSI after spinal surgery $[8,9]$. In particular, for elderly subjects aged $>60 \mathrm{y}$, the incidence of SSI after spinal surgery increases significantly. It has been reported that the risk of SSI after spinal surgery in the elderly aged $\geq 60 \mathrm{y}$ is 3 times higher than that in the younger age group [10]. Schoenfeld et al. [11] analyzed 126 patients with SSI secondary to spinal internal fixation via the posterior approach 
and found that the risk of postoperative infection in patients aged $60-70 \mathrm{y}, 71-80 \mathrm{y}$, and $\geq 81 \mathrm{y}$ was significantly higher than that in those aged $\leq 59 \mathrm{y}$. Fang et al. [10] reviewed 1,095 patients undergoing spinal internal fixation via the posterior approach; the average age of SSI patients was $47.8 \mathrm{y}$. Among the 48 patients with SSI, 17 were $>60$ y old, accounting for $35.4 \%$ of the patients with infection. Thus, it was concluded that patients aged $>60 \mathrm{y}$ had a higher risk of SSI. In the present study, advanced age was also a factor of SSI following spinal surgery. According to logistic regression analysis, the OR value of SSI after spinal surgery in elderly patients in this study was about 3 . The immune systems of elderly patients degenerate, and they typically have multiple underlying diseases. In our study, of the 4,350 patients undergoing spinal internal fixation via the posterior approach, 1,680 were aged $>60 \mathrm{y}$ old. Elderly patients always present with degeneration of the immune system, mostly accompanied by multiple underlying diseases. Heart disease leads to a decline in the cardiac ejection capability and a decrease in blood supply to the tissues. Moreover, the decrease in local blood supply causes weakness of local resistance and self-healing ability in the body that increases the infection risk. In addition, hypertension can cause vascular lesions and reduce the local blood supply to the surgical site.

Long surgical duration will increase the risk of SSI secondary to spinal internal fixation via the posterior approach. Long surgical duration increases the risk of wound infection in patients that may be caused by the extension of surgical duration, increased duration of tissue traction; further, soft-tissue traction leads to local tissue ischemia and necrosis. The extension of surgical duration also increases the chance of wound contamination in patients. Our study showed that the rate of postoperative SSI increased significantly in patients with surgical duration $>3 \mathrm{~h}$. Apisarnthanarak et al. [12] reported that the incidence of postoperative infection increased significantly when the duration of spinal surgery was $>3 \mathrm{~h}$. In addition, combined diabetes is an important risk factor for incision infection in patients undergoing spinal surgery. A relevant study showed that the risk of postoperative infection in diabetic patients was much higher than that in non-diabetic patients [13]. Abdul-Jabbar et al. [14] retrospectively analyzed 6,628 hospitalized surgical patients and found that diabetes significantly increased the SSI risk. Olsen et al. [13] considered diabetes as an independent risk factor for SSI. Our results showed that diabetes was correlated with SSI after spinal surgery. The OR value of patients with diabetes was 4.47 , indicating that the risk of postoperative infection in patients with diabetes was nearly 4 times higher than that in patients without diabetes. SSI after spinal surgery in patients with diabetes is mainly associated with diabetesrelated autoimmune disorders, decreased wound healing ability, and capillary lesions. Diabetic microangiopathy can cause local tissue ischemia and hypoxia and reduce the antibiotic concentration in tissues [15]. The immune cell function of patients with diabetes is damaged, leading to relative inhibition of the immune function of the body. If there is pathogen invasion, it is very prone to infection [16]. The function of platelet-derived growth factor in patients with diabetes is also affected, resulting in a decline in the wound healing ability. Moreover, serum albumin concentration $<30 \mathrm{~g} / \mathrm{L}$ was an independent risk factor for postoperative SSI, consistent with the report by Klein et al. [17]. Further, intraoperative blood loss $>1,000 \mathrm{~mL}$ combined with postoperative hidden blood loss [18] is another independent risk factor for postoperative SSI. Severe anemia can reduce the ability of tissue repair and anti-infection, increasing the risk of postoperative infection. Research [19] has shown that when the hemoglobin level is $<80 \mathrm{~g} / \mathrm{dL}$, the 
oxygen-carrying capacity of blood is seriously reduced, and local tissue hypoxia reduces the local resistance to infection. In addition, patients with anemia present with a severe shortage of transporters needed to repair tissues, thereby leading to the decrease in the local repair ability and susceptibility to infection, consistent with the results of our study. This investigation showed that all patients underwent routine blood biochemical examination after the surgery; the postoperative changes in albumin, hemoglobin, and other nutritional status indicators were detected timely, and treatment was given. Moreover, the patients were asked to strengthen their nutritional status and eat a high-protein diet. Parenteral nutrition support was needed when the nutritional status indicators were very poor. Some patients also required albumin infusion and blood transfusion.

How to reduce the incidence of SSI secondary to spinal internal fixation via the posterior approach has always been a challenging issue. First, the surgical indications should be strictly grasped, and surgical treatment can be considered after ineffective conservative treatment. Second, underlying diseases should be controlled and treated. For elderly patients with anemia and low serum albumin concentration, the underlying diseases and general conditions should be strictly evaluated, blood glucose should be actively controlled, and anemia and hypoalbuminemia should be corrected. In this study, although smoking was not a risk factor for SSI following spinal surgery, smoking cessation could effectively improve respiratory function, increase functional residual capacity, and reduce the incidence of postoperative pulmonary complications. Therefore, patients with long-term smoking should give up smoking for $2 \mathrm{wk}$ before the surgery [20]. If necessary, lung CT and lung function tests should be performed to evaluate the lung condition of patients. Our study showed that the beginning time of surgery was not a risk factor for SSI following spinal infection. However, on the morning of one day, surgeons are energetic and can perform the operation more precisely. Reasonable design of the surgical plan, the concept of small incision, minimal invasion, and reduction in intraoperative blood loss and surgical duration are needed. The aseptic management of the operating room should be strengthened, and the aseptic concept of surgeons and nurses should be improved. Furthermore, postoperative care should be strengthened, patients should be guided toward early activities, postoperative wound management should be improved, the wound status should be frequently monitored, and antibiotics should be administered reasonably as per the wound and the general conditions. The risk factors are relatively independent; however, more often, they are interrelated and influenced by each other. To reduce infection rate, rather than controlling a certain factor in isolation, we need to understand the basic condition of patients with respect to all the aspects and design a reasonable treatment plan as per the condition. Only in this way can we effectively reduce the rate of SSI secondary to spinal internal fixation via the posterior approach.

This study also has certain limitations, such as the fact that only one spinal cord research center in Western China was the study setting. Considering the cross-sectional nature of this study, causality between the results and the investigation variables could not be evaluated. In order to better understand the risk factors related to infection secondary to spinal internal fixation via the posterior approach in China, a longitudinal cohort study is required for a deeper understanding of the factors involved in the infection after spinal surgery and the effects of these factors on the infection rate. Moreover, the inclusion of non-randomly selected participants may lead to unpredictable biases. Despite the above limitations, 
this study identified factors closely related to infection secondary to spinal internal fixation via the posterior approach and proposed improvement strategies and intervention measures that will ultimately reduce the infection rate after spinal surgery.

\section{Conclusion}

This study provides information regarding SSI secondary to spinal internal fixation via the posterior approach. We found that age $>60 \mathrm{y}$, surgical duration $>3 \mathrm{~h}$, serum albumin concentration $<30 \mathrm{~g} / \mathrm{L}$, hemoglobin concentration $<80 \mathrm{~g} / \mathrm{L}$, combined diabetes, and blood loss $>1,000 \mathrm{~mL}$ are directly correlated with SSI secondary to spinal internal fixation via the posterior approach. These findings may contribute to discussions and actions that may help in reducing SSI secondary to spinal internal fixation via the posterior approach in the short or medium term.

\section{Abbreviations}

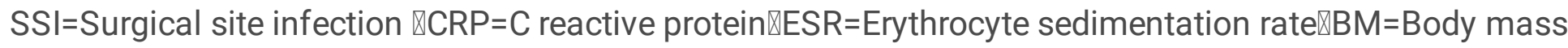
index.

\section{Declarations}

\section{Acknowledgements}

Not applicable.

\section{Funding}

This study was funded by Shaanxi Provincial People's Hospital Science and Technology Talent Program Project (No.2021BJ-28).

The Shaanxi Provincial People's Hospital Science and Technology Talent Program Project had no role in the study design, collection, analysis and interpretation of data nor in the writing of the manuscript and in the decision to submit the manuscript for publication.

\section{Availability of data and materials}

The datasets supporting the conclusions of this article are included within the article. The raw data can be requested from the corresponding author on reasonable request.

\section{Authors' contributions}


XiangHui Dong and Yongchun Zhou participated in the recruitment, data collection and analysis. All authors contributed to the study design and drafting of the manuscript. All authors read and approved the final manuscript.

\section{Ethics approval and consent to participate}

Ethical approval from the Ethics Committee of the Shaanxi Provincial People's Hospital (No. 20200127) was obtained for this study. Each author certifies that all investigations were conducted in conformity with ethical principles. Written informed consent was obtained from all patients included in the study.

\section{Consent for publication}

All patients signed informed consent to publish their personal details in this article.

\section{Competing interests}

The authors declare that they have no competing interests.

\section{References}

1. Ban KA, Minei JP, Laronga C, Harbrecht BG, Jensen EH, Fry DE, Itani KM, Dellinger EP, Ko CY, Duane TM. American College of Surgeons and Surgical Infection Society: Surgical Site Infection Guidelines. J Am Coll Surg. 2016; 224(1): 59-74.

2. Pull ter Gunne AF, Hosman AJ, Cohen DB, Schuetz M, Habil D, van Laarhoven CJ, van Middendorp JJ. A methodological systematic review on surgical site infections following spinal surgery: part 1: risk factors. Spine. 2012; 37(24): 2017-2033.

3. Takahashi H, Wada A, lida Y, Yokoyama Y, Katori S, Hasegawa K, Shintaro T, Suguro T. Antimicrobial prophylaxis for spinal surgery. J Orthop Sci. 2009; 14(1): 40-44.

4. Mazzie JP, Brooks MK, Gnerre J. Imaging and management of postoperative spine infection. Neuroimaging Clin N Am. 2014; 24(2): 365-374.

5. Chen SH, Lee $\mathrm{CH}$, Huang KC, Hsieh PH, Tsai SY. Postoperative wound infection after posterior spinal instrumentation: analysis of long邓term treatment outcomes. Eur Spine J. 2015; 24(3): 561ه570.

6. Koutsoumbelis S, Hughes AP, Girardi FP, Cammisa FP Jr, Finerty EA, Nguyen JT, Gausden E, Sama AA. Risk factors for postoperative infection following posterior lumbar instrumented arthrodesis. $J$ Bone Joint Surg Am. 2011; 93(17): 1627-1633.

7. Watanabe M, Sakai D, Matsuyama D, Yamamoto Y, Sato M, Mochida J. Risk factors for surgical site infection following spine surgery: efficacy of intraoperative saline irrigation. J Neurosurg Spine. 
2010; 12(5): 540-546.

8. Maragakis LL, Cosgrove SE, Martinez EA, Tucker MG, Cohen DB, Perl TM. Intraoperative fraction of inspired oxygen is a modifiable risk factor for surgical Isite infection after spinal surgery. Anesthesiology. 2009; 110(3): 556-562.

9. Kanafani ZA, Dakdouki GK, El-Dbouni O, Bawwab T, Kanj SS. Surgical site infections following spinal surgery at a tertiary care center in Lebanon:incidence, microbiology, and risk factors. Scand J Infect Dis. 2006; 38(8): 589-592.

10. Fang A, Hu SS, Endres N, Bradford DS. Risk factors for infection after spinal surgery. Spine. 2005; 30(12): 1460-1465.

11. Schoenfeld AJ, Carey PA, Cleveland AW 3rd, Bader JO, Bono CM. Patient factors,comorbidities, and surgical characteristics that increase mortality and complication risk after spinal arthrodesis:a prognostic study based on 5887 patients. Spine J. 2013; 13(10): 1171-1179.

12. Apisarnthanarak A, Jones M, Waterman BM, Carroll CM, Bernardi R, Fraser VJ. Risk factors for spinal surgical-site infections in a community hospital:a case-control study. Infect Control Hosp Epidemiol. 2003; 24(1): 31-36.

13. Olsen MA, Nepple JJ, Riew KD, Lenke LG, Bridwell KH, Mayfield J, Fraser VJ. Risk factors for surgical site infection following orthopaedic spinal operations. J Bone Joint Surg Am. 2008; 90(1): 62-69.

14. Abdul-Jabbar A, Takemoto S, Weber MH, Hu SS, Mummaneni PV, Deviren V, Ames CP, Chou D, Weinstein PR, Burch S, Berven SH. Surgical site infection in spinal surgery: description of surgical and patient-based risk factors for postoperative infection using administrative claims data. Spine. 2012; 37(15): 1340-1345.

15. Friedman ND, Sexton DJ, Connelly SM, Kaye KS. Risk factors for surgical site infection complicating laminectomy. Infect Control Hosp Epidemiol. 2007; 28(9): 1060-1065.

16. Carragee EJ, Deyo RA, Kovacs FM, Peul WC, Lurie JD, Urrútia G, Corbin TP, Schoene ML. Clinical research: is the spine field a mine field?. Spine. 2009; 34(5): 423-430.

17. Klein JD, Hey LA, Yu CS, Klein BB, Coufal FJ, Young EP, Marshall LF, Garfin SR. Perioperative nutrition and postoperative complications in patients undergoing spinal surgery. Spine. 1996; 21(22): 26762682.

18. Lei F, Li Z, He W, Tian X, Zheng L, Kang J, Feng D. Total and hidden blood loss between open posterior lumbar interbody fusion and transforaminal lumba rinterbody fusion by Wiltse approach. Medcine. 2020; 99(20): e19864.

19. Osterhoff G, Burla L, Werner CM, Jentzsch T, Wanner GA, Simmen HP, Sprengel K. Role of preoperative blood transfusion and subcutaneous fat thickness as risk factors for surgical site infection after posterior thoracic spine stabilization. Surg Infect. 2015; 16(3): 333-337.

20. Anderson PA, Savage JW, Vaccaro AR, Radcliff K, Arnold PM, Lawrence BD, Shamji MF. Prevention of Surgical Site Infection in Spine Surgery. Neurosurgery. 2017; 80(3): 114-123. 